\title{
Naesohwangryeon-tang Induced Apoptosis and Autophagy in A549 Human Lung Cancer Cells
}

\author{
Hong Jae Kim', Jin-Woo Jeong ${ }^{2}$, Cheol Park³ ${ }^{3}$ Yung Hyun Choi ${ }^{114}$, Su Hyun Hong ${ }^{1,4 *}$ \\ ${ }^{1}$ Anti-Aging Research Center, Dong-eui University, Busan 47340, Republic of Korea \\ 2 Freshwater Bioresources Utilization Bureau, Nakdonggang National Institute of Biological Resoureces, Gyeongsangbuk-do 37242, Re- \\ public of Korea \\ ${ }^{3}$ Department of Molecular Biology, College of Natural Sciences and Human Ecology, Dong-eui University, Busan 47340, Republic of Korea \\ ${ }^{4}$ Department of Biochemistry, Dong-eui University College of Korean Medicine, Busan 47227, Republic of Korea
}

\section{Key Words}

A549 Lung Cancer Cells, Apoptosis, Autophagy, Caspases, Naesohwangryeon-tang, Reactive Oxygen Species

\begin{abstract}
Objectives: Naesohwangryeon-tang (NHT) is a type of traditional herbal formula, however, little is known about its antitumor activity. In this study, the antitumor properties of NHT was evaluated in human lung adenocarcinoma cells.
\end{abstract}

Methods: To check the inhibitory effect of NHT, MTT assay was performed. Cell cycle analysis and detection of ROS production were conducted by flow cytometry. To evaluate the signaling pathway, Western blotting was conducted.

Results: Our results showed that the decrease of cell proliferation by NHT stimulation occurred more significantly in A549 cells than in NCI-H460 cells. In addition, NHT-induced apoptosis was associated with the activation of caspases and production of reactive oxygen species (ROS). NHT-induced apoptosis was attenuated after pretreatments with $\mathrm{z}$-VAD-fmk or $\mathrm{N}$-acetylcysteine,

$\overline{\text { Received: Sep 25, } 2019 \text { Reviewed: Nov 15, } 2019 \quad \text { Accepted: Nov 15, } 2019}$

$@$ This is an Open-Access article distributed under the terms of the Creative Common Attribution Non-Commercial License (http://creativecommons.org/licenses/by-nc/4.0/) which permits unrestricted noncommercial use, distribution, and reproduction in any medium, provided the original work is properly cited.

(2) This paper meets the requirements of KS X ISO 9706, ISO 9706-1994 and ANSI/NISO Z39.48-1992 (Permanence of Paper). suggesting that NHT-induced apoptosis was caspaseand ROS-dependent. Interestingly, NHT treatment led to the development of autophagic vesicular organelles and upregulation of several autophagy-related genes. The pretreatment of bafilomycin Al decreased apoptosis slightly but increased cell viability in the presence of NHT.

Conclusion: These findings indicated that NHT induces both apoptosis and cell-protective autophagy in human lung cancer cells. This data suggests that NHT might be a novel herbal drug for lung cancer.

\section{Introduction}

Cancer is one of the most important life science-related problems globally, and among them, lung cancer has the highest morbidity and mortality rates in both genders $[1,2]$. Early-stage lung cancer patients can be treated with surgical operations, but in many cases, patients are diagnosed after the lung cancer has progressed to an advanced stage and this indicates a poor prognosis consequently. For the last several decades, lung cancer patients were treated with chemotherapy, but the average survival length of patients who received this treatment was 10 months, which was unsatisfactory. Moreover, the side effects caused by the toxicity of anticancer medications may affect the patients' quality of life, and there are often problems caused by the tolerance of anticancer medications $[3,4]$. Therefore, developing a new highly effective anticancer medication

"Corresponding Author

Su Hyun Hong. Department of Biochemistry, Dong-eui University College of Korean Medicine, Busan 47227, Republic of Korea.

Tel: +82-51-850-8644 Fax: +82-51-853-4036

E-mail: hongsh@deu.ac.kr 
with few side effects is necessary.

Autophagy is a fundamental process for cell biology and an evolutionarily conserved pathway that degrades macromolecules including glycogen, lipids, proteins and nucleotides and turnovers organelle $[5,6]$. Autophagy is kwon to have essential roles to maintain the cellular homeostasis, therefore, the deficiency of autophagy is one of the main reason for many diseases including neurodegenerative diseases, inflammation, Crohn's disease and cancer $[7,8]$. According to the past researches, medications using natural multi-target molecules through multiple mechanisms are reported to control the growth and progression of cancer more effectively than medication using mono-target molecules [9]. Combination therapy, with its synergistic effect of multiple active ingredients, improves the treatment effect of chemotherapy and radiation therapy on cancer cells, while protecting normal cells, reducing inflammation on the surrounding tissues of malignant tumors, improving the immune system, and increasing the quality of life of patients and their life expectancy [10]. Thus, in this study, the Naesohwangryeon-tang (NHT), was selected as a candidate for treating lung cancer. NHT, which appears in Donguibogam, the traditional medical book of Korea and also famous internationally, is a multi-herb formula consisting of 12 medications (Table 1). In a previous experimental study, NHT was known to have an antioxidant, antibacterial, and anticancer abilities [11]. However, there has been no study on the activation of lung cancer cell apoptosis, autophagy, and its mechanisms.

Accordingly, we investigated the growth-inhibition effect and associated mechanisms of NHT on lung cancer cells in two non-small cell lung cancer cell lines, A549 and NCI-H460 cells. It was observed that NHT induced apoptosis and autophagy of the lung cancer cells, and it was also associated with an increase of reactive oxygen species inside the cell. The findings of this study indicated the possibility of NHT to be applied in the treatment of lung cancer.

\section{Materials and Methods}

\subsection{Chemicals and Antibodies}

RPMI 1640 medium, fetal bovine serum (FBS) and penicillin/streptomycin were obtained from WelGENE (Daegu, Republic of Korea). 3-(4,5-Dimethyl-2-thiazolyl)-2,5-diph-

Table 1 Composition of Nasohwangryun-tang extact

\begin{tabular}{|c|c|c|}
\hline Scientific Name & Raw material amount (g) & Component ratio $(\%)$ \\
\hline Rheum undulatum L. & 8.0 & 16.7 \\
\hline Forsythia Viridissima Lindl. & 6.0 & 12.5 \\
\hline Paeonia lactirlora Pall. & 6.0 & 12.5 \\
\hline Coptis japonica & 4.0 & 8.3 \\
\hline Scutellaria baicalensis Georgi & 4.0 & 8.3 \\
\hline Angelica gigas & 4.0 & 8.3 \\
\hline Gardenia jasminoides & 4.0 & 8.3 \\
\hline Areca catechu L. & 4.0 & 8.3 \\
\hline Inula helenium L. & 2.0 & 4.2 \\
\hline Mentha arvensis var. piperascens & 2.0 & 4.2 \\
\hline Platycodon grandiflorum (Jacq.) A. DC. & 2.0 & 4.2 \\
\hline Glycyrrhiza glabra L. & 2.0 & 4.2 \\
\hline Total & 48 & 100 \\
\hline
\end{tabular}


nyl-2H-tetrazolium bromide (MTT), 4,6-diamidino-2-phenylindole (DAPI), 2',7'-Dichlorofluorescin diacetate (DCFDA), N-Acetyl-L-cysteine (NAC) and Bafilomycin Al were purchased from Sigma-Aldrich Chemical Co. z-VAD-fmk was obtained from Calbiochem, Inc. The final concentration of DMSO in all experiments was $0.1 \%$. Cyto-ID ${ }^{\circledR}$ Autophagy detection kit was obtained from ENZO Life Sciences, Inc. (NY, USA) Antibodies against poly (ADP-ribose) polymerase (PARP), Bid, caspase-3, -8, -9, $\beta$-actin, Peroxidase-labelled donkey anti-rabbit and sheep anti-mouse immunoglobulin were purchased from Santa Cruz Biotechnology (Santa Cruz, CA, USA). Beclin-1, MAP1 light chain 3 (LC3) and autophagy-related gene 7 (Atg7) was obtained from Cell Signaling Inc. (Beverly, MA, USA). An enhanced chemiluminescence (ECL) Western detection reagents were purchased from Thermo Scientific (Waltham, MA, USA).

\subsection{Preparation of NHT extract}

The components of NHT were purchased from Daehansaengyak (Busan, Republic of Korea). NHT is a multi-herbs formula which is composed of twelve herbs according to "Dongeuibogam" (Table 1). Each herb in NHT was washed cleanly and cut into small pieces. The mixture was extracted with $500 \mathrm{ml}$ of boiling water for $3 \mathrm{~h}$. The extracted water was filtered twice to remove insoluble materials. And then, the filtered water was lyophilized and crushed into a thin powder. The NHT powders were dissolved in distilled water to $100 \mathrm{mg} / \mathrm{ml}$ (stock solution) and diluted with media to the desired concentration prior to use.

\subsection{Cell Culture and Cell Viability Assay}

Human non-small-cell lung cancer (NSCLC) A549 and NCI-H460 cells were purchased from the American Type Culture Collection (Manassas, VA, USA) and maintained in RPMI 1640 medium supplemented with $10 \%$ heat-inactivated FBS and $1 \%$ penicillin/streptomycin. The cells were maintained in a humidified incubator with $5 \% \mathrm{CO} 2$ at $37^{\circ} \mathrm{C}$. A549 and $\mathrm{H} 460$ cells $(1 \times 105$ cells/well $)$ were seeded in 6-well culture plates (SPL Life Science, Pocheon, Republic of Korea). The cells were treated with various concentrations of NHT for $24 \mathrm{~h}$, and then incubated with $0.5 \mathrm{mg} /$ $\mathrm{mL} \mathrm{MTT}$ at $37^{\circ} \mathrm{C}$ for $2 \mathrm{~h}$ in the dark. After a total incubation of $24 \mathrm{~h}$, cell viability was measured using an MTT assay. Next, DMSO was added to each well to dissolve formazan crystals. After gently shaking the plates, the absorbance of each well was measured at $540 \mathrm{~nm}$ with an enzyme-linked immunosorbent assay (ELISA) reader (Molecular Devices, Sunnyvale, CA, USA).

\subsection{DAPI Staining}

To analyze the morphological changes of nuclei, DNA staining was performed with 4',6-diamidino-2-phenylindole (DAPI), fluorescent dye. The cells were washed with phosphate-buffered saline (PBS), fixed with $3.7 \%$ paraformaldehyde and stained with $3 \mu \mathrm{g} / \mathrm{mL}$ of DAPI. The stained cells were then washed twice with PBS and captured with a fluorescence microscopy (Carl Zeiss, Goettingen, Germany).

\subsection{Cell cycle analysis}

Cells were harvested using trypsin-EDTA, washed with PBS and stained with propidium iodide using the BD Cycle TEST PLUS DNA Reagent Kit (BD Biosciences, MA, USA). The protocol followed for cell cycle analysis according to the manufacturer's protocol. Cell cycle distribution was measured with a flow cytometer (BD Biosciences). CellQuest software was used to determine the level of apoptotic cells containing sub-G1 DNA content, based on the presence of red fluorescence.

\subsection{Western Blot Analysis}

Cells were harvested at the indicated time points, and then lysed with lysis buffer (20 mM sucrose, $1 \mathrm{mM}$ EDTA, $20 \mu \mathrm{M}$ Tris-Cl, pH 7.2, 1 mM dithiothreitol, $10 \mathrm{mM} \mathrm{KCl,} 1.5$ $\mathrm{mM} \mathrm{MgCl} 2$, and $5 \mu \mathrm{g} / \mathrm{ml}$ aprotinin) containing protease inhibitors. Protein concentration was determined by the Bio-Rad Protein Assay reagent according to the manufacturer's instruction. The appropriate amounts of cell lysates $(30 \mu \mathrm{g})$ were separated at SDS-polyacrylamide gel electrophoresis and then transferred onto nitrocellulose membranes (Amersham, GE Healthcare Life Sciences, USA). The membranes were blocked with 5\% skim milk in PBST (phosphate-buffered saline with $0.1 \%$ Tween 20 ) for $1 \mathrm{~h}$, washed with PBST and then incubated with various antibodies overnight at $4^{\circ} \mathrm{C}$. After blocking the membranes subsequently incubated with the appropriate secondary antibodies conjugated to horseradish peroxidase. The protein bands were then visualized by an ECL detection system.

\subsection{Measurement of ROS Generation}

Cells were pretreated with or without NAC $(10 \mathrm{mM})$ for 1 $\mathrm{h}$ and then incubated NHT $(2 \mathrm{mg} / \mathrm{ml})$ for indicated times. Cells were then incubated with DCFH-DA $(10 \mu \mathrm{M})$ for 30 minutes at $37^{\circ} \mathrm{C}$. Before harvest, the cells were washed twice with phosphate-buffered saline (PBS). Cells were harvested with trypsin-EDTA and then suspended in PBS. The cells were immediately analysed with a flow cytometer (BD Biosciences), and then placed on a slide for the immediate observation of fluorescence, using a fluorescence microscope (Carl Zeiss).

\subsection{Autophagy detection assay}

Autophagic vacuoles generation was determined using Cyto-ID ${ }^{\circ}$ Autophagy detection kit. Cells were seeded in each well of culture slide. After $24 \mathrm{~h}$, cells were treated with different concentrations of NHT and incubated for another 24 h. Cyto-ID ${ }^{\diamond}$ Autophagy detection kit was used according to the manufacturer's protocol. The slides were analysed with a fluorescence microscope (Carl Zeiss). 


\subsection{Statistical Analysis}

All data are presented as the mean \pm standard deviation (SD). Significant differences among groups were determined using the unpaired Student's t-test. A p-value $<0.05$ was considered to indicate statistical significance. The results shown in each of the figures in this article are representative of at least three independent experiments. All of the figures shown in this article were obtained from at least three independent experiments.

\section{Results}

\subsection{Inhibition of cell viability and mor- phological changes by NHT in A549 and $\mathrm{NCl}-\mathrm{H} 460$ cells}

A549 and NCI-H460 cells were treated with 0, 0.4, 0.8, 1.2, 1.6 , or $2 \mathrm{mg} / \mathrm{ml}$ of NHT. After $24 \mathrm{~h}$ of incubation, cell proliferation was examined by the MTT assay. NHT decreased cell viability in a dose-dependent manner (Fig. 1A). Interestingly, extensive cellular vacuoles were observed in both A549 and NCI-H460 cells after NHT treatment. In A549 cells, at the concentration of approximately $1.2 \mathrm{mg} / \mathrm{mL}$, accompanied by a rapid change in cell shape, the inner vacuoles were distinctly verified, and as the concentration increased, the total cell counts decreased distinctively compared to that in the control group, which was not treated with drugs. In NCI-H460 cells, the intracellular vesicles were distinctly visible in low concentrations of NHT, but the overall change in cell shape, depending on the rise of concentration, appeared less compared to that in A549 cells (Fig. 1B). Such results display the cell proliferation inhibition effect of NHT, accompanied by a distinct cellshape modification effect, when treated in two lung cancer cells. Moreover, A549 cells showed a higher sensitivity to NHT than NCI-H460 cells, and the investigation on the cause and mechanism of apoptosis was processed with A549 cells accordingly.

\subsection{NHT induces apoptosis in human lung cancer A549 cells}

Apoptosis is a typical type of programmed cell death, and it can be induced by targeting only the cancer cells. Thus, the relationship between the NHT-induced A549 lung cancer cell growth suppression effect and apoptosis was investigated. First, the structure of the nucleus was observed using DAPI dye and an optical microscope, and the

A

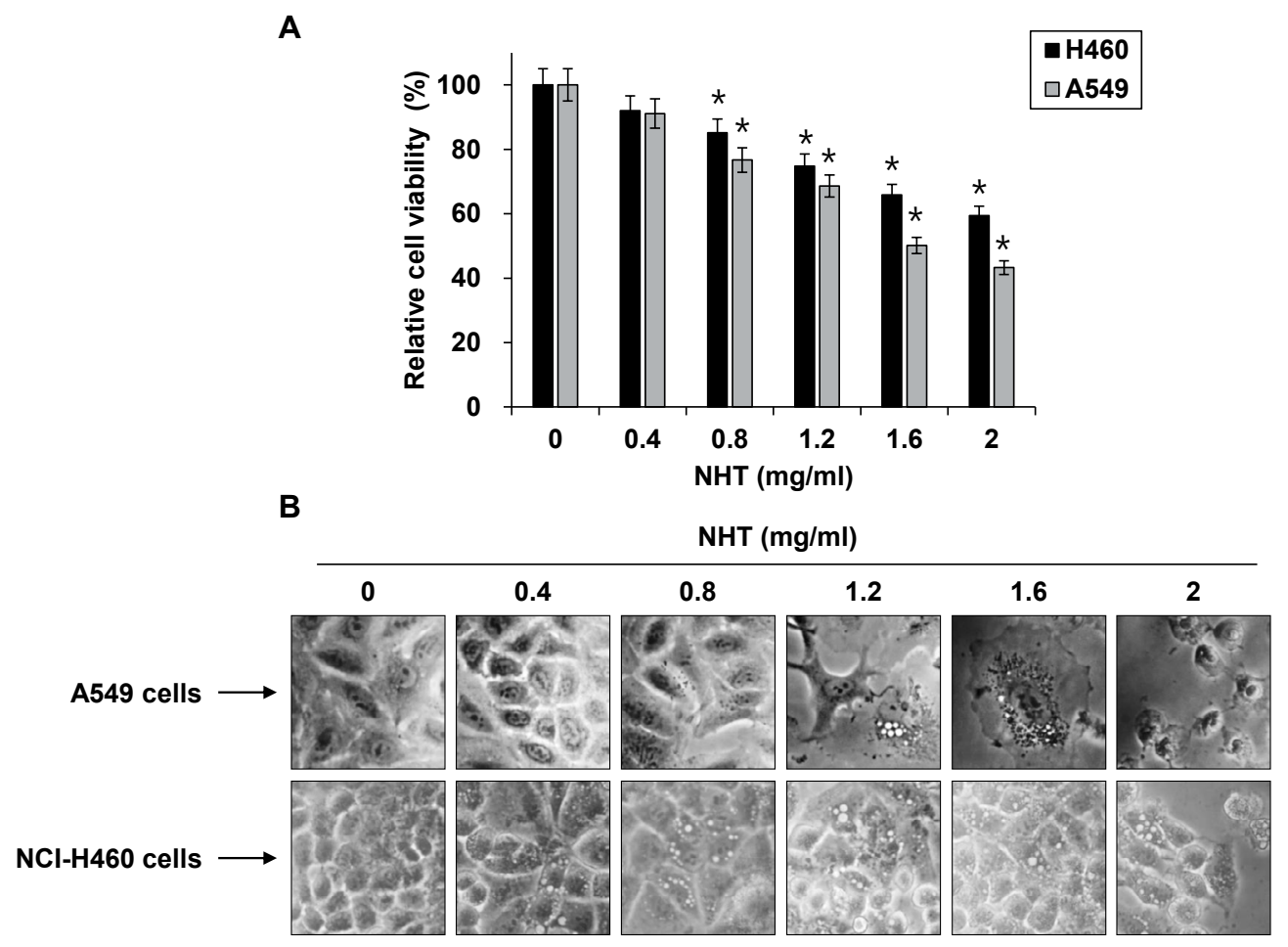

Figure 1 Anti-proliferative effects of NHT in A549 and NCI-H460 human non-small lung cancer cells (A) A549 and NCI-H460 cells were incubated for $24 \mathrm{~h}$ with various concentrations $(0.4-2.0 \mathrm{mg} / \mathrm{ml})$ of NHT. Cell viability was determined by MTT assay. The results presented here are from one representative experiment of three performed that showed similar patterns. Data are the mean \pm SD of three independent experiments. ${ }^{*} \mathrm{p}<0.05$ indicates statistically significant differences between the control group and NHT treatment groups. (B) Cellular morphological changes in A549 and NCI-H460 cells incubated with NHT for 24 h were examined under inverted microscopy (magnification, x200). 
A

$\mathrm{NHT}(\mathrm{mg} / \mathrm{ml})$

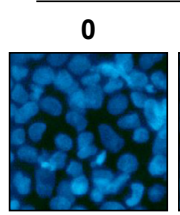

$$
0.5
$$

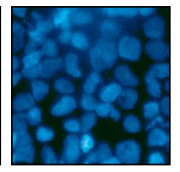

1

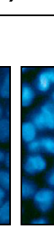

1.5
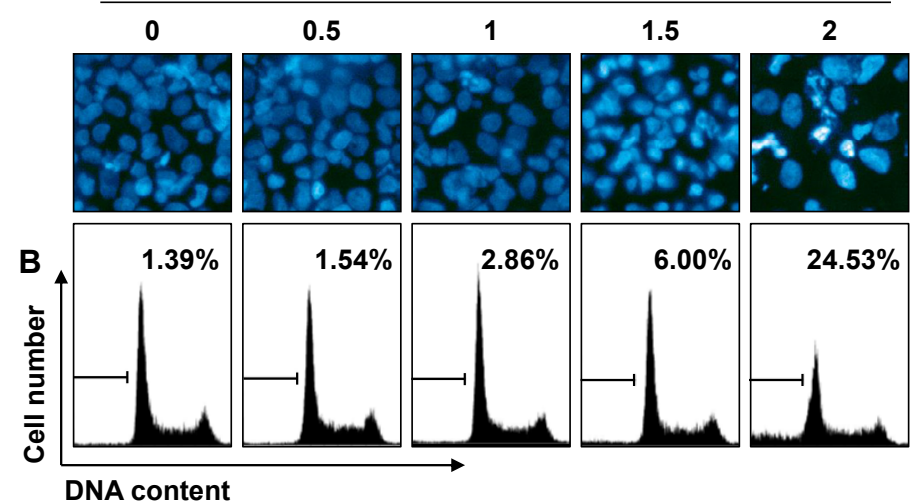

DNA content

Figure 2 NHT treatment significantly induced apoptosis in A549 cells. A549 cells were incubated for $24 \mathrm{~h}$ with indicated concentrations of NHT. (A) Cells were stained with DAPI for $10 \mathrm{~min}$ and photographed with a fluorescence microscope using a blue filter (magnification, $\mathrm{x} 400$ ). (B) To further evaluate the effects of NHT on A549 cell proliferation inhibition was related with apoptosis, we determined the cell cycle distribution by flow cytometry. NHT-treated cells were collected and sub-G1 DNA content evaluated using a flow cytometry.

A
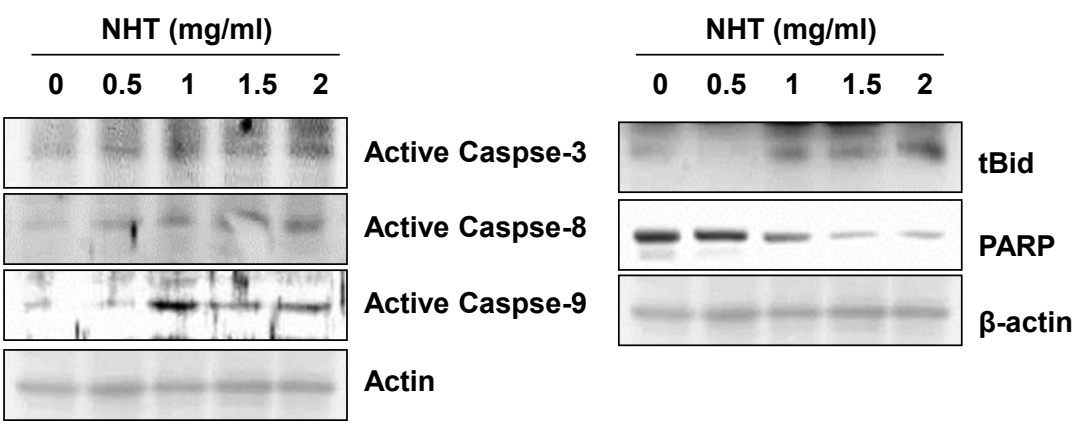

B
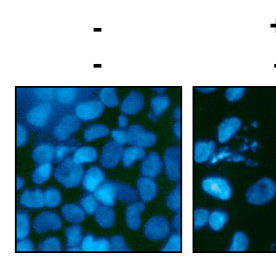

Actin

C

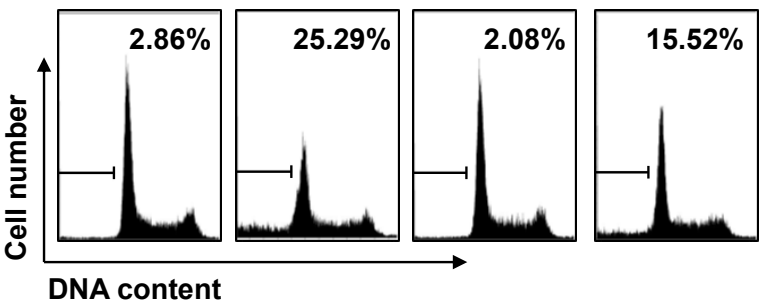

$+\quad \mathrm{NHT}(2 \mathrm{mg} / \mathrm{ml})$

$-$
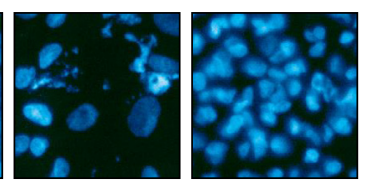

$+$

z-VAD-fmk (10 $\mu \mathrm{M})$

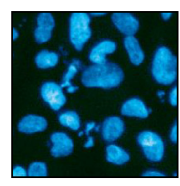

DNA content

Figure 3 NHT-induced apoptosis was involved with activation of caspases in A549 cells. A549 cells were incubated for $24 \mathrm{~h}$ with indicated concentrations of NHT. (A) To investigate the changes in the expression of caspases, bid and PARP at the protein level, Western blotting was performed. The cells were lysed and then equal amounts of cell lysates were separated on SDS-polyacrylamide gels and transferred to nitrocellulose membranes. The membranes were probed with the indicated antibodies and the proteins were visualized using an ECL detection system. Actin was used as an internal control. (B) Cells were stimulated with $2 \mathrm{mg} / \mathrm{ml} \mathrm{NHT}$ for $24 \mathrm{~h}$ with or without of pretreatment with $10 \mu \mathrm{M}$ z-VAD-fmk, a pan-caspase inhibitor, for $1 \mathrm{~h}$. To investigate the morphologic change, DAPI staining was carried out. (C) To quantify the degree of apoptotic cells, cells were collected and sub-G1 DNA content evaluated using a flow cytometry. Data are the mean \pm SD of three independent experiments. 
fragmentation of the nuclei, typical in cells going through apoptosis, was observed in cells treated with $2 \mathrm{mg} / \mathrm{mL}$ NHT for 24 h (Fig. 2A). Subsequently, PI dye and flow cytometry were used to examine the cell cycles. Similar to the DAPI dye results, the number of sub-G1-type cells increased by approximately 17 times compared to the normal cells when treated with $2 \mathrm{mg} / \mathrm{mL}$ NHT. According to such results, NHT seemed to induce apoptosis, and the mechanism was investigated.

\subsection{Mechanism of apoptosis induced by NHT}

Caspase (cysteine-aspartic proteases) is known to play a pivotal role in inducing apoptosis by being degraded se- quentially in response to various stimuli that occur inside or outside the cell $[12,13]$. Through Western blotting, it was found that in response to NHT treatment, the active form of caspase-3, -8 , and -9 increased, and the change in the BID truncated form, which amplifies the activation of effector caspses-3 and Poly ADP ribose polymerase (PARP) was verified. To identify more roles of caspase in NHT treatment, the caspase inhibitor z-VAD-fmk was treated before treating with NHT, and the number of subG1-type cells decreased by $60 \%$ compared to treatment with NHT only (Fig. 3C). According to the result, it may be inferred that NHT-induced apoptosis is related to the partially caspase-dependent pathway.

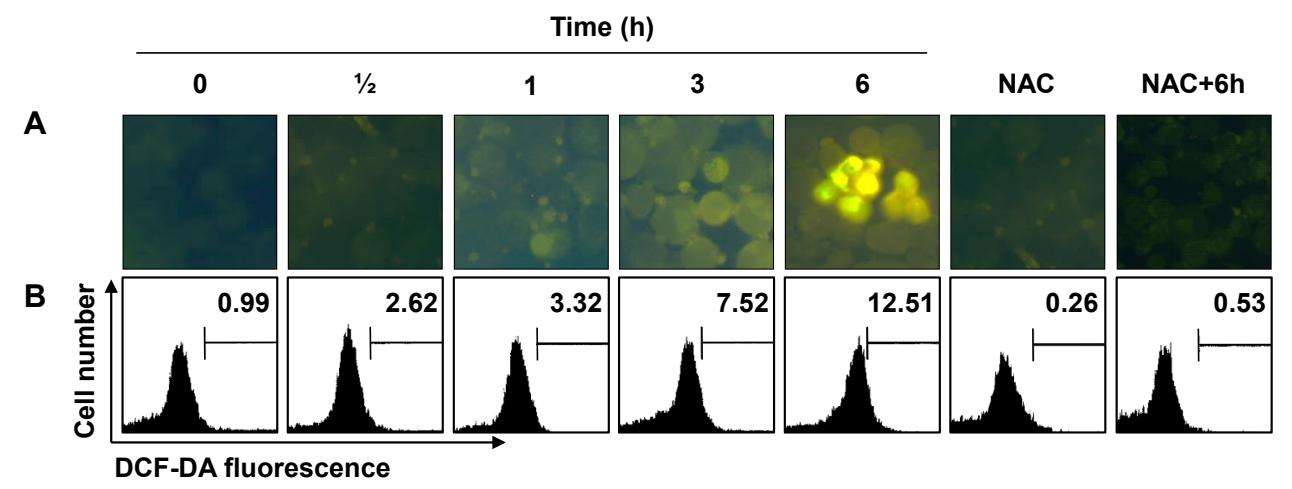

Figure 4 Effect of NHT on intracellular ROS generation in A549 cells (A and B) In order to observe the accumulation of ROS, the cells were photographed with a fluorescence microscope and analyzed with FACS. A549 cells were stimulated by NHT for the indicated time with or without pre-treatment of $10 \mathrm{mM}$ NAC, a ROS scavenger, for $1 \mathrm{~h}$. The level of ROS production was detected with H2DCFDA for 30 min. Data are the mean \pm SD of three independent experiments.

A

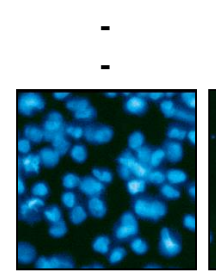

B

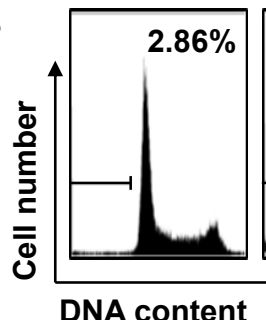

$+$

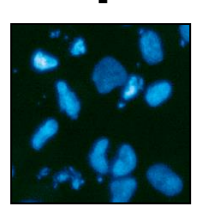

$25.29 \%$

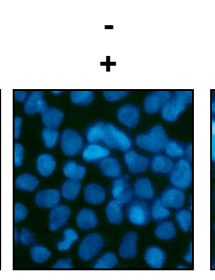

$+\quad \mathrm{NHT}(2 \mathrm{mg} / \mathrm{ml})$

$+\quad$ NAC (10 mM)
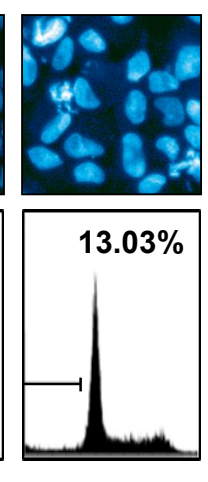
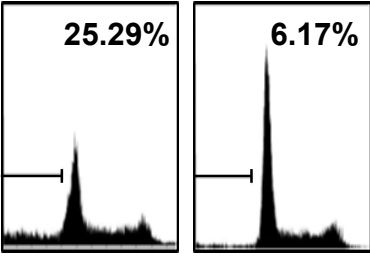

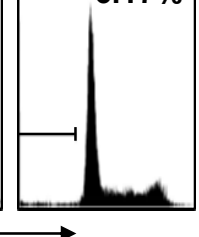

$\longrightarrow$<smiles>[CH]C</smiles>

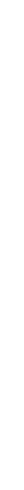

Figure 5 NHT-induced cell death was partially associated with the generation of ROS. (A) Cells were stimulated with $2 \mathrm{mg} / \mathrm{ml}$ NHT for $24 \mathrm{~h}$ with or without of pretreatment with $10 \mathrm{nM}$ NAC for $1 \mathrm{~h}$. To investigate the morphologic change, DAPI staining was carried out. (B) To quantify the degree of apoptotic cells, cells were collected and sub-G1 DNA content evaluated with a flow cytometry. Data are the mean \pm SD of three independent experiments. 


\subsection{Effects of NHT on ROS generation in A549 cells}

Many drugs derived from plants are known to have an anticancer effect by increasing the generation of ROS and inducing apoptosis [14-16]. NHT was expected to increase the production of ROS in A549 cells, and the quantity of generated ROS was measured. After NHT treatment for $30 \mathrm{~min}$ to $6 \mathrm{~h}$, the level of ROS increased as the treatment period increased and in the group treated with NHT for $6 \mathrm{~h}$, the amount of ROS increased by approximately 13 times compared to that in the control group without NHT treatment (Fig. 4B). To investigate the correlation between the occurrence of ROS and the inducement of apoptosis, after $1 \mathrm{~h}$ of preprocessing by an NAC ROS scavenger, 2 $\mathrm{mg} / \mathrm{mL}$ of NHT was administered over $24 \mathrm{~h}$ and the cycle was analyzed using a DAPI dye and flow cytometry. After NAC treatment, there was a tendency in the cell numbers and shape of the nuclei to recover to their normal status (Fig. 5A) and the number of cells corresponding to sub-G1 decreased by $50 \%$ compared to those being treated independently by NHT (Fig. 5B). This result shows that NHT plays an important role in inducing apoptosis via the occurrence of ROS.

\subsection{NHT induces autophagy in A549 cells}

To investigate the relationship between the appearance of unusual vacuoles in the cytoplasm specific to NHT treatment and autophagy, the cells were dyed and exam- ined using the cyto-ID kit and DAPI, which specifically dyes autophagic vacuoles and nuclei, respectively. As shown in Figure 6A, when treated with NHT, the bright and distinct dyed points were observed in the cytoplasm (red points) and not the DAPI-dyed nucleus. These points disappear by preprocessing with the inhibitor of the late phase of autophagy, bafilomycin A. Moreover, autophagy is a multi-phase process and is accompanied by the organic change of proteins LC3, ATG (autophagy-related gene), and Beclin-1 [6]. By NHT treatment, the conversion from LC3 I to LC3 II and the expression of Beclin-1 and ATG 7 were increased, and such changes were more distinct as the concentration of NHT increased (Fig. 6B). Such data show that NHT not only induces apoptosis but also induces autophagy.

\subsection{Function of NHT-induced autophagy in A549 cells}

The correlation of NHT-induced apoptosis and autophagy and the cell growth suppression effect of autophagy were investigated. When $10 \mathrm{nM}$ bafilomycin was prepared for $1 \mathrm{~h}$, the nucleus cleavage was slightly reduced and the sub-G1 population decreased by approximately $20 \%$ than when treated with NHT independently (Fig. 7A \& 7B), and cell growth suppression, as detected by the MTT assay, The correlation of NHT-induced apoptosis and autophagy and the cell growth suppression effect of autophagy were investigated. When $10 \mathrm{nM}$ bafilomycin was prepared for $1 \mathrm{~h}$, the nucleus cleavage was slightly reduced and the sub-G1 population decreased by approximately $20 \%$ than

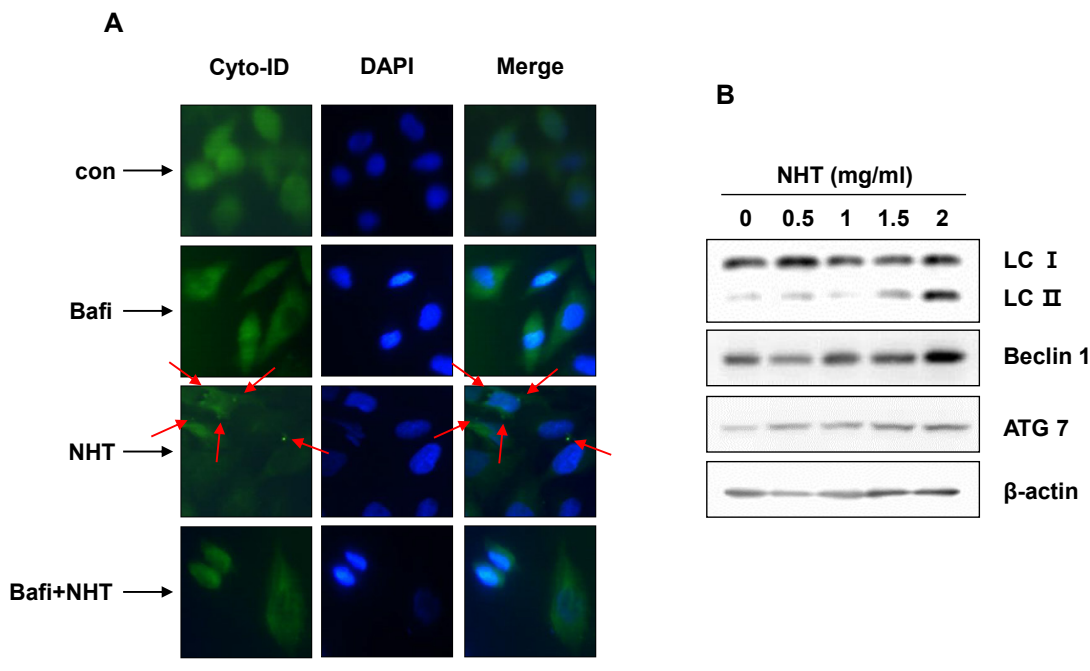

Figure 6 NHT induced autophagy in A549 cells. (A) NHT treated-A549 cells were incubated for $24 \mathrm{~h}$ with or without $1 \mathrm{~h}$ pretreatment of bafilomycin Al (Bafi). Following the incubation, both NHT-untreated (con) and NHT-treated cells were stained with Cyto-ID ${ }^{\circ}$ Green autophagy dye and DAPI. Using fluorescence microscopy the accumulation of green fluorescence, indicating the specificity for autophagy detection was photographed. (B) Effects of NHT on the levels of LC3, Beclin-1 and ATG7 were examined in A549 cells. The cells were treated with the indicated concentrations of NHT in for $24 \mathrm{~h}$. Proteins on Western blots were detected with the indicated antibodies and ECL detection system. B-actin was used as an internal control. 
A

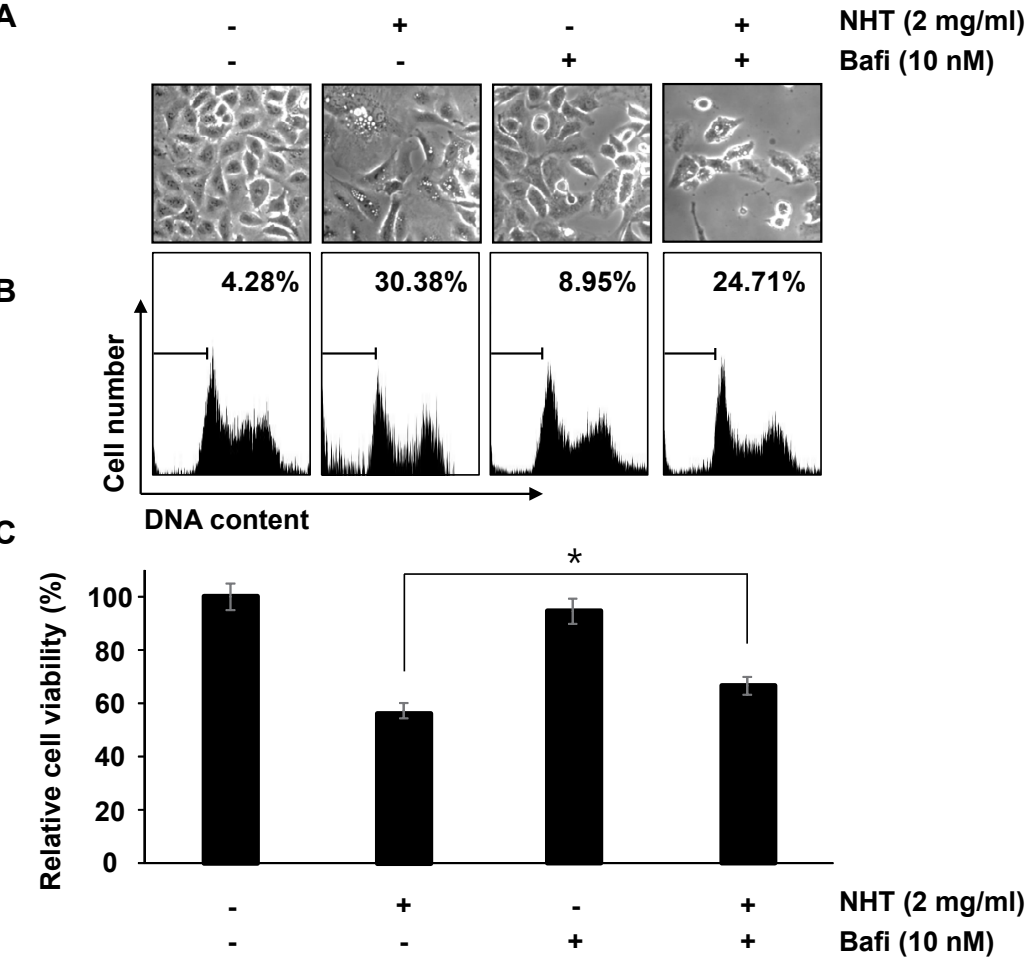

Figure 7 Autophagy inhibition by bafilomycin A1 (Bafi) promoted NHT-Induced cell death in A549 cells. To further study about NHT-induced autophagy in A549 cells, A549 cells were treated with NHT for $24 \mathrm{~h}$ after pretreatment or not with $10 \mathrm{nM}$ bafilomycin A1. (A) Morphologic changes were shown using microscopy (magnification, x200). (B) The amount of sub-G1 DNA content was quantified using a flow cytometry. (C) The cell viability was measured by MTT assay. Data are the mean \pm SD of three independent experiments. * $<<0.05$ indicates statistically significant differences between the control group and NHT treatment groups.

when treated with NHT independently (Fig. 7A \& 7B), and cell growth suppression, as detected by the MTT assay, increased by approximately $20 \%$ (Fig. $7 \mathrm{C}$ ). Although it is difficult to draw a conclusion from such results, it may be interpreted that NHT-induced autophagy suppresses the induction of apoptosis to some degree, and because the cell growth suppression caused by the suppression of autophagy was not observed, it may be said that the NHT-induced autophagy is not an autophagic cell death.

\section{Discussion}

A malignant tumor is caused by imbalances between endogenous physical conditions of the body and exogenous pathogenic factors according to the theories of traditional Korean medicines (TKMs) or traditional Chinese medicines (TCMs). When the whole body's immune system fails, pathogenic factors can attack the person, leading to cancer development and progression [10,17]. While Western medicine has one molecule and mechanism only as the treatment target, TCM and TKM with many types of medication or ingredients integrated may be the new al- ternative to lung cancer treatments. Thus, in this study, the effects of inducing apoptosis and autophagy anticancer mechanisms of NHT were investigated.

Apoptosis is an ancient form of highly regulated cell death that acts under physiological and pathological conditions. An extensive study has characterized caspases as the key executioner of apoptotic processes [12]. Recent research indicates that caspases are involved in cell death mediated by apoptosis as well as autophagy, pyroptosis, and necroptosis. Caspases play a diverse role to maintain the homeostasis of a cell, but in the present study, the investigation is focused on the initiator caspases, caspase-8 and -9 , which have an important role in apoptotic cell death, and on caspase-3, an effector caspase. Caspase- 9 is activated through the influence of cytochrome $\mathrm{c}$ when it is emitted to the cytoplasm via induced mitochondrial outer membrane permeabilization in the mitochondria or the Bcl-2-regulated (intrinsic) pathway. On the other hand, caspase-8 directly induces apoptosis through binding to the death-inducing signaling complex, which is formed by ligand-binding in the death receptor (extrinsic) pathway. On the other hand, caspase-8 directly induces apoptosis through binding to the death-inducing 
signaling complex, which is formed by ligand-binding in the death receptor (extrinsic) pathway. Bid, a substrate of caspase-8, is a pro-apoptotic Bcl-2 family protein and amplifies the intrinsic mechanism via the truncated form BID $[18,19]$. Caspase-8 and -9 ultimately activate apoptosis via the cleavage of various cellular substrates including PARP, through activating executioner caspases, such as caspase-3 [20]. In this study, it was found that the NHT treatment increases the active form of the caspase-3, -8, and -9 , accompanied by the cleavage of the Bid and PARP, it was showed that the NHT treatment is related to boththe intrinsic and extrinsic pathways

In addition, NHT also induced not only apoptosis but also autophagy. Autophagy is fundamental for cell biology and an evolutionarily conserved pathway that degrades macromolecules, including glycogen, lipids, proteins, and nucleotides and turnovers cellular organelle [8]. Autophagy is known to have essential roles to maintain cellular homeostasis; therefore, the deficiency of autophagy is one of the main reasons for many diseases, including neurodegenerative diseases [21], Crohn's disease [22], and cancer $[23,24]$. Although the understanding of the physiologic and pathological function of autophagy is increasing and the interest in the association of autophagy in malignant tumors is rising, the importance of the function of autophagy in anticancer treatment is still unclear $[25,26]$. The results of many studies support that autophagy has a protective role of cells and helps survival of cells in response to various stimuli, including anticancer treatment and radiation therapy $[3,27,28]$. However, a clinical study performing autophagy inhibition using anticancer drugs with 35 different anti-cancer treatments did not report an increase in the susceptibility of the treatments, excluding few cases [29]. Other authors have also reported on autophagic cell death and such results support that autophagy is not associated in the cell-protecting role only [30,31]. In the study, the function and relationship between the NHT-induced autophagy and apoptosis were investigated, and it was found that autophagy plays a role in the suppression of a part of apoptosis, and according to the autophagy suppression leading to a small increase in the survival rate of cells, the NHT-induced autophagy seems to be associated with cell-protective functions and not autophagic cell death. However, to understand its exact role, further research must be supplemented.

In conclusion, the findings of this present study suggested that NHT induced apoptosis in A549 lung cancer cells, and such is partially suppressed by autophagy. With its lung cancer cell proliferation suppression effect, NHT may be used as the new lung cancer treatment medication in combination with the other therapies with less side effects and higher treatment effects.

\section{Acknowledgement}

This research was supported by Dong-eui University Grant (No. 201902130001) and Basic Science Research Program through the National Research Foundation of Korea (NRF) grant funded by the Korea government (No. 2019R1F1A1058094).

\section{Conflict of interest}

The authors declare that there is no conflict of financial interest.

\section{References}

1. Siegel R, Naishadham D, Jemal A. Cancer statistics. CA Cancer J Clin. 2012;62(1):10-29.

2. Cho KM, Keam B, Kim TM, Lee SH, Kim DW, Heo DS. Clinical efficacy of erlotinib, a salvage treatment for non-small cell lung cancer patients following gefitinib failure. Korean J Intern Med. 2015;30(6):891-8.

3. Wu T, Wang MC, Jing L, Liu ZY, Guo H, Liu Y, et al. Autophagy facilitates lung adenocarcinoma resistance to cisplatin treatment by activation of AMPK/mTOR signaling pathway.Drug Des Devel Ther 2015;9:6421-31.

4. Kapp FG, Sommer A, Kiefer T, Dölken G, Haendler B. 5-alpha-reductase type I (SRD5A1) is up-regulated in non-small cell lung cancer but does not impact proliferation, cell cycle distribution or apoptosis. Cancer Cell Int. 2012;12(1):1.

5. Pyo JO, Nah J, Jung YK. Molecules and their functions in autophagy. Exp Mol Med. 2012;44(2):73-80

6. Mizushima N, Yoshimorim T, Levine B. Methods in mammalian autophagy research. Cell. 2010;140(3):31326.

7. Choi KS. Autophagy and cancer. Exp Mol Med. 2012;44(2):109-20.

8. Levine B, Kroemer G. Autophagy in the pathogenesis of disease. Cell. 2008;132(1):27-42.

9. Khan M, Maryam A, Zhang H, Mehmood T, Ma T. Killing cancer with platycodin $\mathrm{D}$ through multiple mechanisms. J Cell Mol Med 2016;20(3):389-402.

10. Hsiao WL, Liu L. The role of traditional Chinese herbal medicines in cancer therapy-from TCM theory to mechanistic insights. Planta Med. 2010;76(11):1118-31.

11. An BJ, Lee CE, Son JH, Lee JY, Park TS, Park JM, er al. Antioxidant, Anticancer and antibacterial Activities of Naesohwangryntang and its Ingredients, Kor J Herbology. 2005;20(4):17-26.

12. Yi CH, Yuan J. The Jekyll and Hyde functions of caspases. Dev Cell. 2009;16(1):21-34.

13. Nuñez G, Benedict MA, Hu Y, Inohara N. Caspases: the proteases of the apoptotic pathway. Oncogene. 1998;17(25):3237-45.

14. Na PY, Chye SM, Ng ChH, Koh RY, Tiong YL, Pui LP, et al. Clinacanthus Nutans Hexane Extracts Induce Apoptosis Through a Caspase-Dependent Pathway in Human Cancer Cell Lines. Asian Pac J Cancer Prev. 2017;18(4):917-26.

15. Choi EO, Park C, Hwang HJ, Hong SH, Kim GY, Cho EJ, et al. Baicalein induces apoptosis via ROS-dependent activation of caspases in human bladder cancer 5637 cells. Int J Oncol. 2016;49(3):1009-18.

16. Hua P, Sun M, Zhang G, Zhang Y, Tian X, Li X, et al. Cepharanthine induces apoptosis through reactive oxygen species and mitochondrial dysfunction in human non-small-cell lung cancer cells. Biochem Biophys Res 
Commun. 2015;460(2):136-42.

17. Macek C. East meets West to balance immunologic yin and yang. JAMA. 1984;251(4):433-5, 439.

18. Shalini S, Dorstyn L, Dawar S, Kumar S. Old, new and emerging functions of caspases. Cell Death Differ. 2015;22(4):526-39.

19. Graf RP, Keller N, Barbero S, Stupack D. Caspase-8 as a regulator of tumor cell motility. Curr Mol Med. 2014;14(2):246-54.

20. Park C, Cha HJ, Choi EO, Lee H, Hwang-Bo H, Ji SY et al., Isorhamnetin Induces Cell Cycle Arrest and Apoptosis Via Reactive Oxygen Species-Mediated AMP-Activated Protein Kinase Signaling Pathway Activation in Human Bladder Cancer Cells. Cancers (Basel). 2019;11(10),1494.

21. Vijayan V, Verstreken P. Autophagy in the presynaptic compartment in health and disease. J Cell Biol 2017;216(7):1895-1906.

22. Hooper KM, Barlow PG, Stevens C, Henderson P. Inflammatory Bowel Disease Drugs: A Focus on Autophagy. J Crohns Colitis. 2017;11(1):118-127.

23. Kimmelman AC. The dynamic nature of autophagy in cancer. Genes Dev. 2011;25(19):1999-2010.

24. Lin SR, Fu YS, Tsai MJ, Cheng H, Weng CF. Natural Compounds from Herbs that can Potentially Execute as Autophagy Inducers for Cancer Therapy. Int J Mol Sci. 2017;18(7):1412.

25. Lorin S, Hamaï A, Mehrpour M, Codogno P. Autophagy regulation and its role in cancer. Semin Cancer Biol. 2013;23(5):361-79.

26. Rosenfeldt MT, Ryan KM. The role of autophagy in tumour development and cancer therapy. Expert Rev Mol Med. 2009;11:e36.

27. Wang Y, Zhang J, Huang ZH, Huang XH, Zheng WB, Yin $\mathrm{XF}$, et al. Isodeoxyelephantopin induces protective autophagy in lung cancer cells via Nrf2-p62-keap1 feedback loop. Cell Death Dis. 2017;8(6):e2876.

28. Yu L, Shang ZF, Hsu FM, Zhang Z, Tumati V, Lin YF, et al. NSCLC cells demonstrate differential mode of cell death in response to the combined treatment of radiation and a DNA-PKCs inhibitor. Oncotarget. 2015;6(6):3848-60.

29. Saleh T, Cuttino L, Gewirtz DA. Autophagy is not uniformly cytoprotective: a personalized medicine approach for autophagy inhibition as a therapeutic strategy in non-small cell lung cancer. Biochim Biophys Acta. 2016;1860(10):2130-6.

30. Chung SJ, Nagaraju GP, Nagalingam A, Muniraj N, Kuppusamy P, Walker A, et al. ADIPOQ/adiponectin induces cytotoxic autophagy in breast cancer cells through STK11/LKB1-mediated activation of the AMPK-ULK1 axis. Autophagy. 2017;13(8):1386-1403.

31. Fulda S. Autophagy in Cancer Therapy. Front Oncol. 2017;7:128. 